УДК 621.791 .92

И.Р. Шакиров, И.И. Загиров, Р.Н. Сайфуллин

РАСЧЕТ ТЕМПЕРАТУРЫ НАГРЕВА И ПРЕДЕЛА ТЕКУЧЕСТИ

ПРИСАДОЧНОЙ ПРОВОЛОКИ ПРИ ЭЛЕКТРОКОНТАКТНОЙ ПРИВАРКЕ

Ключевые слова: электроконтактная приварка; присадочная проволока; контакт; деформация; предел текучести; температура. 
Введение. Обоснованно считается, что электроконтактная приварка стальных проволок (ЭКПП) является одним из наиболее эффективных способов восстановления наружных цилиндрических поверхностей с износами до $0,6 \ldots$ 0,8 мм на сторону $[1,14-16]$. Общеизвестно [15 и др.], что сварное соединение при восстановлении деталей ЭКПП образуется в твердой фазе, а его прочность определяется степенью пластической деформации присадки. При максимально достижимом значении относительной осевой деформации проволоки $\varepsilon_{y}=0,44 \ldots 0,46$ прочность приварки металлопокрытия к валу достигает предела на разрыв основного металла детали. В свою очередь, величина и интенсивность пластической деформации зависят как от химического состава присадочного металла, так и от состояния присадочной проволоки при еe нагреве импульсом сварочного тока, т. е. от режимов приварки. Изучение деформационных процессов, происходящих при формировании сварного соединения в твердой фазе, позволяет обоснованно подойти к выбору рациональных режимов технологического процесса ЭКПП. Измерение температуры нагрева присадочного металла связано с большими трудностями. Наши попытки таких измерений с применением термопар не увенчались успехом. Размещенные в просверленных в проволоках отверстиях микротермопары в большинстве случаев разрушаются при термомеханическом цикле приварки.

Цель работы - разработать методику и определить температуру нагрева и предел текучести металла присадочной проволоки расчетным путем.

Оборудование и материалы. В Башкирском ГАУ процесс ЭКПП осуществляется на установке электроконтактной наплавки модели 011-1-02 конструкции ГОСНИТИ. Инструмент ролик-электрод из бронзы НТБ диаметром 300 мм с шириной рабочей части 12 мм. Наиболее часто для восстановления деталей применяется присадочная проволока ПК-2 ГОСТ 938975 диаметром 1,8 мм. Химический состав этой присадки соответствует стали 65Г. Методы исследования применялись аналитические.

Составление расчетной схемы. При осадке разогретая импульсом сварочного тока присадочная проволока образует с поверхностями детали и инструмента контакты. О форме таких контактных площадок с цилиндрическими поверхностями вала и инструмента можно судить по рисунку 1. Считается, что контуры контактов ограничиваются полуэллиптическими кривыми [3-5]. Продольные полуоси таких геометрических фигур в дальнейшем будем называть дугами контактов и обозначать их длины соответственно $L_{1}$ и $L_{2}$. Поперечные полуоси, равные половине ширины сварного валика, при больших деформациях присадочной проволоки практически одинаковы на площадках со стороны вала и со стороны инструмента $b_{1}=b_{2}=b$.

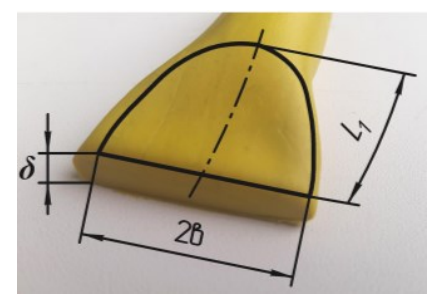

Рисунок 1

Пластическая модель

формирования контактных площадок

Составлена приведенная на рисунке 2 расчетная схема для определения параметров формирования сварного соединения. На рисунке 3 показана развертка контактной площадки присадки с поверхностью вала и действующие на присадочный металл усилия. К валу 1 роликомэлектродом 2 прижимается присадочная проволока 3 , которая при прохождении импульса тока разогревается до пластического состояния и осаживается, образуя контактные площадки 4 и 5 с валом и рабочей поверхностью инструмента. Единичные контактные площадки перекрываются по их длине и ширине, поэтому на детали формируется сплошное металлопокрытие 6 . В зоне контактов выделена элементарная призма 7 , положение которой определяется центральными углами $\alpha_{1}$ и $\alpha_{2}$.

Расчеты параметров контактных площадок. 1) При осадке присадочный металл проволоки подвергается трехмерной пластической деформации. Осевую относительную составляющую $\varepsilon_{y}$ определяем, сравнивая исходную длину присадочной проволоки $L_{\Pi P}$ и длину сварного валика $L_{B}$, сформированного из этой проволоки:

$$
\varepsilon_{y}=\frac{L_{\mathrm{B}}-L_{\Pi P}}{L_{\Pi P}} .
$$

2) Толщина металлопокрытия $\delta$ определяется без непосредственного измерения по зависимости:

$$
\delta=\frac{\pi \cdot d^{2}}{4 \cdot S \cdot\left(1+\varepsilon_{y}\right)},
$$

где $S$ - шаг приварки сварного валика по винтовой линии.

Здесь, как и в дальнейшем, раскрываем лишь обозначения, не указанные на расчетных схемах (рисунки 2, 3).

3) После приварки проволоки на вал замеряем на последнем, не перекрываемом витке металлопокрытия его ширину $2 b$.

4) Длины контактных дуг замерами не определяются. Рассчитываем их аналитически. По схеме на рисунке 2 получаем следующие геометрические соотношения:

$$
\begin{gathered}
t_{1}+t_{2}+\delta=d, \\
\cos \alpha_{1,2}^{M A X}=\left(R_{1,2}-t_{1,2}\right) / R_{1,2}, \\
L_{1,2}=R_{1,2} \cdot \alpha_{1,2}^{M A X} .
\end{gathered}
$$




\section{DOI: 10.31563/1684-7628-2017-42-2-88-93}

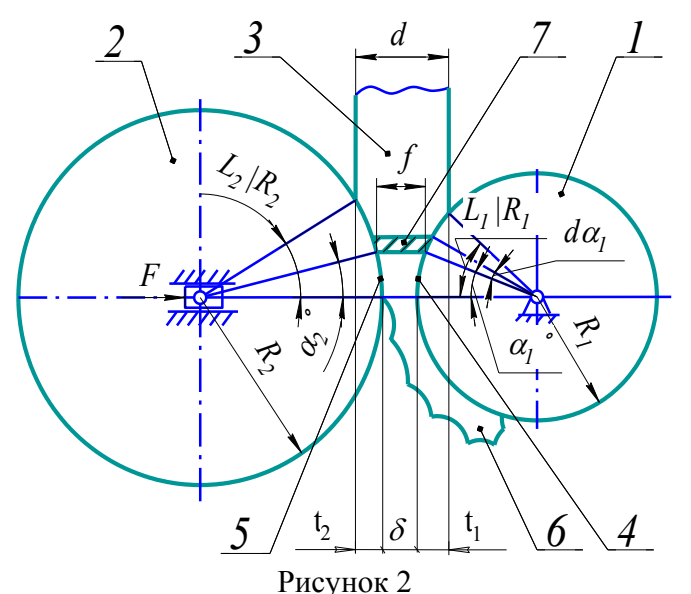

Формирование металлопокрытия при ЭКПП: 1 - вал; 2 - наплавляющий ролик; 3 - присадочная проволока; 4 - контактная площадка со стороны образца; 5 - контактная площадка со стороны ролика-электрода; 6 - металлопокрытие; 7 - элементарная призма

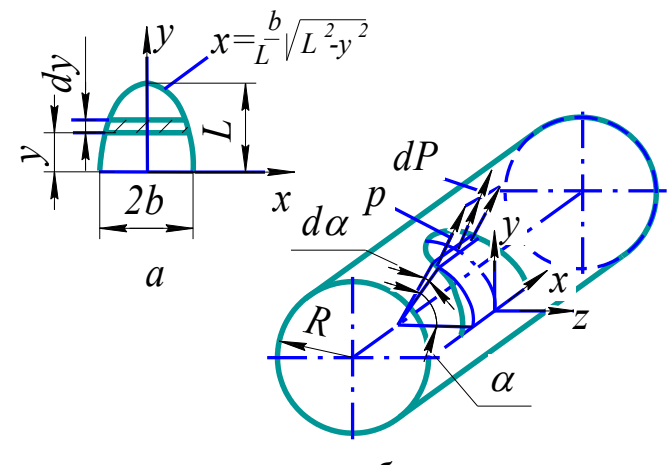

6

Рисунок 3

Развертка площадки контакта между образцом и присадочным металлом $(a)$ и напряжения на выделенном элементе (б)
Дополнительно к формулам (3-5) выводим уравнение равновесия присадочного металла между валом и роликом-электродом. Для этого определяем площадь боковой поверхности, выделенной на рисунках 2 и 3 элементарной призмы:

$$
d A=R \cdot d \alpha \cdot 2 x=2 \frac{b}{L} \sqrt{L^{2}-R^{2} \cdot \alpha^{2}} \cdot R \cdot d \alpha .
$$

На боковые поверхности выделенного элемента присадочного металла со стороны вала и инструмента действует давление $p$, равное пределу текучести $\sigma_{T}$ присадочного металла при данной температуре, $p=\sigma_{T}$. Усилие, воспринимаемое боковой гранью элементарной призмы, равно $d P=\sigma_{T} \cdot d A$, его проекция на ось $z$ (на направление усилия $\bar{F}$, действующего со стороны инструмента) равна:

$$
d P_{z}=\sigma_{T} \cdot 2 \frac{b_{1} R_{1}{ }^{2}}{L_{1}} \sqrt{\left(L_{1} / R_{1}\right)^{2}-\alpha^{2}} \cdot \cos \alpha \cdot d \alpha \cdot
$$

Просуммируем проекции элементарных сил (7) по площади контактной площадки присадочного металла с валом и получим:

$$
F=2 \sigma_{T} \cdot \frac{b_{1} \cdot R_{1}^{2}}{L_{1}} \cdot \int_{0}^{L_{1} / R_{1}} \sqrt{\left(L_{1} / R_{1}\right)^{2}-\alpha^{2}} \cdot \cos \alpha \cdot d \alpha
$$

Такое же усилие $F$ действует в контакте присадочного металла с рабочей поверхностью ролика-электрода:

$$
F=2 \sigma_{T} \cdot \frac{b_{2} \cdot R_{2}^{2}}{L_{2}} \cdot \int_{0}^{L_{2} / R_{2}} \sqrt{\left(L_{2} / R_{2}\right)^{2}-\alpha^{2}} \cdot \cos \alpha \cdot d \alpha .
$$

Приравняв выражения (8) и (9), с учетом $b_{1}$ $=b_{2}=b$ получаем уравнение равновесия сил, действующих на присадочный металл:

$$
\frac{R_{1}^{2}}{L_{1}} \cdot \int_{0}^{L_{1} / R_{1}} \sqrt{\left(L_{1} / R_{1}\right)^{2}-\alpha^{2}} \cdot \cos \alpha \cdot d \alpha=\frac{R_{2}^{2}}{L_{2}} \cdot \int_{0}^{L_{2} / R_{2}} \sqrt{\left(L_{2} / R_{2}\right)^{2}-\alpha^{2}} \cdot \cos \alpha \cdot d \alpha .
$$

Из (8) получим значение предела текучести

$$
p=\sigma_{T}=\frac{F \cdot L_{1}}{2 b \cdot R_{1}^{2} \cdot \int_{0}^{L_{1} / R_{1}} \sqrt{\left(L_{1} / R_{1}\right)^{2}-\alpha^{2}} \cdot \cos \alpha \cdot d \alpha} .
$$

Длины контактных дуг $L_{1}$ и $L_{2}$ можно вычислить, решая систему уравнений $(3-5,10)$.

5) Определяем температуру нагрева металла присадочной проволоки. Общеизвестно, что характеристики упругости стали с повышением температуры $T$ резко снижаются. В литературных источниках $[6,7]$ приведены формулы для определения предела текучести присадочной стали в зависимости от температуры.

В контактной сварке для определения предела текучести разогретого металла применяют формулу К.А. Кочергина [6]:

$$
\sigma_{T}=\sigma_{T O} \cdot\left(1-T / T_{\Pi л}\right)^{2},
$$

где $T_{\text {Пл }}$ - температура плавления стали; $\sigma_{T O}-$ предел текучести металла в холодном состоянии.

При горячей обработке металлов давлением используют формулу Экеленда [7], учитывающую химический состав присадочного материала:

$$
\sigma_{T}=(140-0,1 \cdot T) \cdot(1,4+C+M n+0,3 \cdot C r) \mathrm{M \Pi а},(13)
$$
где $C, M n, C r-$ содержание в стали углерода, марганца, хрома, \%.

Из литературы известны и другие, аналогичные (12) и (13), зависимости. По приведенным соотношениям $(12,13)$, зная характеристику $\sigma_{T}$, можно определить соответствующую этой характеристике температуру.

Пример расчетов. На цилиндрический образец из стали 45 ГОСТ 1051-88 диаметром 50 мм роликом-электродом диаметром 300 мм была наварена присадочная проволока 1,8 ПК-2 ГОСТ 9389-75 исходной длиной $L_{\Pi P}=500$ мм. В соответствии с исследованиями [8] был выбран оптимальный по критерию «прочность сварного соединения» режим приварки: действующее значение сварочного тока 7,2 кА; окружная скорость вращения образца $22,5 \mathrm{~mm} / \mathrm{c}$; усилие на ролике-электроде 1,3 кН; шаг приварки по винтовой линии 3 мм/об; длительность импульсов тока 0,04 с; длительность пауз между импульсами $0,08 \mathrm{c}$. 
После приварки измерили длину сварного валика $L_{B}=729$ мм и его ширину $2 b=3,5$ мм. По формуле (1) подсчитали относительное удлинение присадочной проволоки $\varepsilon_{y}=0,458$, по формуле (2) - среднюю толщину металлопокрытия $\delta=0,458$ мм. По соотношениям $(3-5,10)$ определили: значения осадок присадочной проволоки со стороны образца и инструмента, соответственно $t_{1}=0,91 \mathrm{мм} ; t_{2}=0,154 \mathrm{мM}$; длины дуг контактных площадок $L_{1}=9,55 \mathrm{Mм} ; L_{2}=9,61 \mathrm{Mм}$.

По формуле (11) определяем предел текучести материала присадочной проволоки для конкретных условий ЭКПП: $\sigma_{T}=46$ МПа.

Затем по зависимости К.А. Кочергина (12) находим температуру присадочной проволоки ПК-2 при рассматриваемом режиме приварки, получаем $T=1200{ }^{\circ} \mathrm{C}$. Приняв по справочным данным [9] $\sigma_{T O}=800 \mathrm{MПа,} T_{\Pi Л}=1540^{\circ} \mathrm{C}$, определяем температуру по формуле (13) Экеленда. Расчет дает практически то же значение температуры $T=1180{ }^{\circ} \mathrm{C}$. Вычисления выполняли в системе MachCad, пользуясь компьютерной программой [10]. Найденные в примере значения $p=$ $\sigma_{T}$ и $T$ являются оптимальными с точки зрения обеспечения максимально достижимой прочности приварки металлопокрытия. При известном из расчета значении $\sigma_{T}$ по формуле (8) вычисляется требуемое усилие $F$ на ролике-электроде.

Выполненные по разработанной методике расчеты показывают, что температура нагрева присадочной проволоки несколько ниже температуры плавления стали. В исследованиях [11, 12] приводятся более высокие значения темпе-

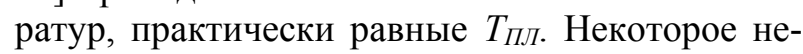
совпадение температур объясняем следующим. По нашей методике определяется температура присадочного металла в конце термомеханического цикла, в момент образования химических связей соединяемых металлов. Через максимальные в конце осадки контактные площадки часть тепловой энергии уходит в массивный ролик-электрод и вал, присадочный металл к этому моменту уже несколько остывает. В указанных же источниках речь идет о максимальных температурах нагрева материала проволоки в стыке основного и присадочного металлов. Наши расчеты также показывают, что при оптимальных режимах восстановления температуры присадочного металла совпадают с рекомендуемыми в источниках [7, 9] температурами нагрева заготовок при горячей обработке металлов давлением. Соответственно для сравниваемых случаев совпадают и пределы текучести материалов. Разработанный способ определения температуры нагрева присадочной проволоки при ЭКПП защищен патентом [13].

Выводы. Составлена методика, а также разработан способ определения температуры нагрева присадочной проволоки при восстановлении деталей ЭКПП, основанные на измерениях параметров пластической деформации присадочной проволоки при ее приварке. Расчеты разработанным способом показали, что температура нагрева присадочного металла, привариваемого на оптимальном по критерию «прочность сварного соединения» режиме, соответствует рекомендуемым для соответствующих марок сталей температурам ковки и горячей штамповки. По полученному уравнению (8) можно вычислить для оптимального варианта приварки необходимое значение усилия на ролике-электроде.

\section{Библиографический список}

1. Нафиков, М.З. Электроконтактная наплавка - эффективный способ восстановления валов [Текст] / М.3. Нафиков // Упрочняющие технологии и покрытия. 2007. № 11. С. 21-24.

2. Каракозов, Э.С. Соединение металлов в твердой фазе [Текст] / Э.С. Каракозов. М.: Металлургия, 1976. $263 \mathrm{c}$.

3. Нафиков, М.3. Формирование сварного с соединения при восстановлении валов контактной приваркой стальной проволоки и сетки [Текст] / М.3. Нафиков, Р.Н. Сайфуллин, Э.Л. Левин, А.П. Павлов // Технология металлов. 2011. № 6. С. 26-31.

4. Нафиков, М.3. Обоснование технологических процессов и разработка технических средств восстановления автотракторных деталей электроконтактной наплавкой [Текст]: дисс. ... докт. техн. наук: 05.20.03 / Марат Закиевич Нафиков. Саранск, 2010. 274 с.

5. Нафиков, М.3. Расчет параметров формирования соединения при электроконтактной наплавке (наварке) проволоки [Текст] / М.3. Нафиков, И.И. Загиров // Сварочное производство. 2008. № 8. С. 15-20.

6. Кочергин, К.А. Контактная сварка [Текст] / К.А. Кочергин. Л.: Машиностроение, 1987. $240 \mathrm{c}$.

7. Громов, И.И. Теория обработки металлов давлением [Текст] / И.И. Громов. М.: Металлургия, 1978. $360 \mathrm{c}$.

8. Нафиков, М.З. Режимы контактной приварки проволоки 1,8 ПК-2 / М.З. Нафиков, И.И. Загиров // Вестник Башкирского государственного аграрного университета. 2012. № 2. С. 45-48.

9. Справочник металлиста. В 5 т. Т. 2 [Текст] / Под ред. А.Г. Рахштадта и В.А. Бростерема. М.: Машиностроение, 1976.718 с.

10. Свидетельство об официальной регистрации программы для ЭВМ № 2006614259. Зона образования соединения в пределах контактных площадок [Текст] / М.3. Нафиков, Р.Н. Сайфуллин, И.И. Загиров. Регистр. 13.12.06. 
11. Клименко, Ю.В. Электроконтактная наплавка (наварка) металлов с плавлением пограничного слоя [Текст] / Ю.В. Клименко // Сварочное производство. 1981. № 8. С. 20.

12. Дубровский, В.А. Предотвращение выплесков при электроконтактной наварке проволокой их стали 40X13 [Текст] / В.А. Дубровский, В.В. Булычев, А.И. Пономарев // Сварочное производство. 2003. № 6. С.12-15.

13. Пат. 2315683 Российская Федерация, МПК В23К11/06, В23К31/12. Способ определения температуры нагрева присадочного металла при электроконтактной наплавке [Текст] / М.3. Нафиков, И.И. Загиров; заявитель и патентообладатель Башкирский государственный аграрный университет. № 2006111300/02; заявл. 06.04.2006; опубл.27.01.08, Бюл. № 3.5 с.
14. Дидманидзе, О.Н. О проблемах организации обслуживания и ремонта техники в условиях сельскохозяйственных предприятий [Текст] / О.Н. Дидманидзе, Т.Е. Митягин, В.Б. Лукьянов // Международный технико-экономический журнал. 2007. № 1 (1). С. 46-49.

15. Юнусбаев, Н.М. Восстановление автотракторных деталей электроконтактной приваркой порошковых материалов в магнитном поле [Текст]: автореф. дис. ... канд. техн. наук / Н.М. Юнусбаев. Уфа: Башкирский ГАУ, 2006.

16. Патент № 2322333 РФ, МПК В23К11/06 Способ электроконтактной приварки металлических порошков [Текст] / Р.Н. Сайфуллин, Э.Л. Левин, М.Н. Фархшатов, Н.М. Юнусбаев, (РФ); опубл. 20.04.2008. Бюл. № 11.

\section{Сведения об авторах}

1. Шакиров Ильшат Рамитович, аспирант кафедры механики и инженерной графики, ФГБОУ BО Башкирский ГАУ, г. Уфа, ул. 50-летия Октября, 34, e-mail: Sh_Ilshat@bk.ru.

2. Загиров Ильнур Илдарович, кандидат технических наук, доцент кафедры механики и инженерной графики, ФГБОУ ВО Башкирский ГАУ, г. Уфа, ул. 50-летия Октября, 34, e-mail: Zagirych22@,mail.ru.

3. Сайфуллин Ринат Назирович, доктор технических наук, профессор кафедры технологии металлов и ремонта машин, ФГБОУ ВО Башкирский ГАУ, г. Уфа, ул. 50-летия Октября, 34, е-таil: bashagregat@mail.ru.

Для исследования деформационных процессов, происходящих при формировании сварного соединения методом электроконтактной приварки, необходимо знать температуру нагрева проволоки и зависящие от нее характеристики упругости присадочного материала. Так как измерение температуры нагрева присадочного металла связано с большими трудностями, задача решалась расчетным методом. Была составлена схема деформации присадки, сформулированы условия ее равновесия между деталью и роли- ком-электродом. На основе выполненных аналитических расчетов определяются температура и предел текучести присадочного металла для конкретных условий восстановления. Приводится пример определения состояния присадочной проволоки при ее приварке. Исследования могут быть использованы при выборе рациональных режимов приварки присадочных проволок, а именно, при определении усилия на ролике-электроде и окружной скорости вращения детали.

I. Shakirov, I. Zagirov, R. Sayfullin

\section{CALCULATION OF WELDING WIRE HEATING TEMPERATURE AND YIELD POINT AT AN ELECTRIC-CONTACT WELDING}

\section{Key words: electric-contact welding; welding wire; contact; deformation; yield point; temperature.}

\section{Authors' personal details}

1. Shakirov Ilshat, Post-graduate student of the mechanics and engineering graphics chair, Federal State Budgetary Educational Institution of Higher Education «Bashkir State Agrarian University», Ufa, 50-letya Oktyabrya, 34, e-mail: Sh_Ilshat@bk.ru.

2. Zagirov Ilnur, Candidate of technical sciences, assistant professor of the mechanics and engineering graphics chair, Federal State Budgetary Educational Institution of Higher Education «Bashkir State Agrarian University», Ufa, 50-letya Oktyabrya, 34, e-mail: Zagirych22@mail.ru.

3. Sayfullin Rinat, Doctor of technical sciences, professor of the metal technology and machines repair, Federal State Budgetary Educational Institution of Higher Education «Bashkir State Agrarian University», Ufa, 50-letya Oktyabrya, 34, e-mail: bashagregat@mail.ru.

To study deformation processes during developing a welding joint by an electric-contact welding it is necessary to know the heating temperature of a wire and dependent on it welding material elasticity features. Since to measure the heating temperature of the welding material is complicated, the heating temperature was determined by the computational method. A scheme of filler material deformation was 
developed; requirements for the balance between the part and the roller electrode were outlined. According to the conducted analytical calculations welding material temperature and yield point for specific restore conditions are determined. The paper illustrates a

(С Шакиров И.Р., Загиров И.И., Сайфуллин Р.Н. case of determining the state of the filler wire in the welding process. The results of the study can be used to select efficient schemes of filler wire welding, namely, to measure the roller-electrode force and the circumferential velocity of a rotating part. 